\title{
ARAŞTIRMA/RESEARCH
}

\section{Abdominal aort anevrizmalarının endovasküler tamirinde Anaconda stent greft ile erken ve orta dönem sonuçları}

\author{
Early and midterm results of endovascular repair of abdominal aortic aneurysms \\ with Anaconda stent graft
}

Uğur Göçen ${ }^{1}$, Atakan Atalay ${ }^{1}$

${ }^{1}$ Çukurova Üniversitesi Tıp Fakültesi, Kalp ve Damar Cerrahisi Anabilim Dalı, Adana, Turkey

Cukurova Medical Journal 2016;41(4):754-761.

\begin{abstract}
Purpose: In this study, we aim to report our midterm results of endovascular replacement of abdominal aortic aneurysms with Anaconda stent graft.

Material and Methods: Between January 2014 and June 2016, a total number of 32 patients who underwent endovascular aortic replacement (EVAR) with Anaconda stent graft electively or emergently were retrospectively analysed. Twenty-nine patients undergoing elective, 2 patients were processed as urgent. Average follow-up was 16.3 months (range, 1-28 months). Mortality, morbidity, survival rates, mean duration of operation, mean length of intensive care unit and hospital stays, the type and incidence of endoleaks, contrast nephropathy rates, the impact on leakage of the aortic diameter, complication rates and secondary intervention rates were recorded.

Results: Early term hospital follow-up no mortality was observed, mortality was observed in one patient due to myocardial infarction one and a half months later. A leg thrombosis of stent occurred in two patients. Embolectomy was performed for one patient, ilio-ilea bypass applied for the other patients. Short-term results in terms of patient satisfaction with endovascular repair of aortic stent grafts anaconda and shows that good in terms of results.

Conclusion: Endovascular aortic replacement (EVAR) can be selected as a treatment option in abdominal aortic aneurysm patients with co-morbidities and high mortality risk. We have received successful results in early and midterm results in our patients with abdominal aortic aneurysm endovascular treatment with Anaconda stent graft.
\end{abstract}

Key words: Abdominal aortic aneurysm; endovascular treatment, anaconda stent graft.

\section{Öz}

Amaç: $\mathrm{Bu}$ çalışmada abdominal aort anevrizmalarının Anaconda stent greft ile endovasküler aort replasmanında orta dönem sonuçlarımızı bildirmeyi amaçladık.

Gereç ve Yöntem: Ocak 2014-Mayıs 2016 tarihleri arasında abdominal aort anevrizması nedeniyle elektif veya acil olarak anaconda stent greft ile endovasküler aort replasmanı (EVAR) yapilan toplam 32 hasta retrospektif olarak incelendi. Yirmi dokuz hasta elektif olarak, 2 hasta acil olarak işleme alındı. Anevrizmaların anatomik dağllımında 18'i infrarenal ve aortoiliyak anevrizma, 14'ü izole abdominal aort anevrizması olarak bildirildi. Hastaların ortalama hastanede kalış süresi 2.2 gün (dağılım, 1-4 gün) idi. Ortalama takip süresi 16.3 ay (dağılım, 1-28 ay) idi. Mortalite, morbidite, sağkalım oranları, ortalama ameliyat süresi, ortalama yoğun bakım ünitesinde ve hastanede kalış süresi, kaçak tipi ve insidansı, kontrast nefropati oranları, aort çapının kaçak üzerindeki etkileri, komplikasyon oranları ve ikincil girișim oranları kaydedildi. Bulgular: Erken dönem hastane takiplerinde mortalite gözlenmezken, bir hastada 1.5 ay sonra miyokard infarktüsü sonrası mortalite gözlendi. İki hastada stentin bir bacağında tromboz gelişti. Bir hastaya embolektomi, diğer hastaya iliyo-iliak bypass yapıldı. Sonuçlar kısa dönemde anaconda stent greft ile endovasküler aort tamirinin hasta memnuniyeti ve sonuçlar açısından iyi olduğunu göstermektedir.

Sonuç: Endovasküler aort replasmanı (EVAR), abdominal aort anevrizmalı ve eşlik eden hastalığ1 ve yüksek mortalite riski olan hastalarda bir tedavi seçeneği olabilir. Anaconda stent greft ile abdominal aort anevrizmasina endovasküler tedavi yaptığımız hastalarımızın erken ve orta dönem sonuçlarında başarılı sonuçlar aldık.

Anahtar kelimeler: Abdominal aort anevrizmasi; endovasküler tedavi, anaconda stent greft. 


\section{GİRİŞ}

Abdominal aort anevrizması toplumda oldukça sık , genellikle ileri yaş grubunda, hipertansif hasta grubunda görülen, birçok morbidite faktörünü beraberinde taşıyan ve görüntüleme yöntemleri ile tesadüfen teşhis edilen bir patolojidir. Anevrizmalar arteriyel sistemin herhangi bir yerinde görülebilirse de yaklaşık \%80'1 abdominal aortta izlenmektedir. $\mathrm{Bu}$ nedenle EVAR en çok infrarenal abdominal aort anevrizmalarında uygulanmaktadır ${ }^{1}$. Abdominal aort anevrizmalarında $>5.0 \mathrm{~cm}$ aort çapının olması, altı ayda $0.5 \mathrm{~cm}$ 'den veya bir ylda $1 \mathrm{~cm}$ 'den fazla büyüme götermesi, veya semptomatik anevrizma endovasküler girişim için endikasyonlardır². Endovasküler yöntem stent-greft teknolojisindeki gelişmeler ile birlikte daha düşük mortalite ve morbidite oranları, daha kısa hastanede kalış süresi ve diğer sistem sorunları bulunan hastalarda da uygulanabilmesi nedeniyle günümüzde giderek daha fazla kullanilmaktadir ${ }^{3}$.

Çalışmalarda açık anevrizma tamirine göre, endovasküler tamirinin, ilk 30 gün içerisindeki mortalite oranını azalttığı bildirilmiştir ${ }^{4}$. Bir başka çalışma grubunda, özellikle endovasküler EVAR ilk 30 günlük mortalite oranı \%1.7 iken aç1k cerrahi grubunda \%4.7 olarak saptanmıştır. Açık cerrahi yöntem sonrası renal ve pulmoner yetmezlik semptomları ile birlikte hastanede kalıș süresi de uzamaktadır. Buna karşın EVAR yapılan olguların büyük çoğunluğunda daha düşük komplikasyon oranıyla, başarılı anevrizma tamiri gerçekleştirilebilmektedir. Ancak damar perforasyonu, işlem sonrası anevrizma kesesinin perfüzyonunu devam etmesi ya da tekrarlaması anlamina gelen kaçaklar ve buna bağlı gelişen ek komplikasyonlar ile stent bacağının kendi üstüne katlanması ya da stent tıkanması gibi farklı sorunlar EVAR'ın dezavantajları olarak ortaya çıkmaktadır ${ }^{5}$. $\mathrm{Bu}$ yüzden gelişebilecek risklerin tanımlanabilmesi için yaşam boyu radyolojik takip önerilmektedir. Çünkü kaçak olsun ya da olmasın anevrizmanın büyümeye devam etmesi, nüksü ve stentin yer değiştirmesi; rüptür riskinin artması ile ilişkilidir ${ }^{6}$. İşte bu sorunlar, endovasküler stent-greftlerin orta ve uzun vadedeki sonuçları bakımından başlıca tartışma konusu yaratmaktadır. EVAR greft komplikasyonlarının tanı ve tedavisi için takip gereklidir7. Güncel EVAR takip önerileri greft komplikasyonları ve kaçakları tespit etmek için en iyi yöntem olarak bilgisayarlı tomografi anjiyografi önerilmektedir ${ }^{7}$. Bilgisayarlı tomografi, ilk izlem muayenesinde kaçak durumunda 1, 6 ve 12 ay sonra tavsiye edilmektedir ${ }^{7}$.

$\mathrm{Bu}$ retrospektif çalışmada, izole abdominal aort anevrizmalarında anaconda stent greft ile endovasküler aortik tamir işlemlerinin erken ve orta dönem sonuçları sunuldu.

\section{GEREÇ VE YÖNTEM}

\section{Hastalar}

Ocak 2014 - Haziran 2016 tarihleri arasinda Çukurova Üniversitesi Tip Fakültesi kalp ve damar cerrahisi kliniğinde aynı ekip tarafindan abdominal aort anevrizmasi nedeniyle anaconda stent greft ile tamir işlemi uygulanan izole abdominal aort anevrizmalı 32 hasta (30 erkek, 2 kadın; ort. yaş $65.1 \pm 8.8 \mathrm{yll}$; dağılım 32-84 y1l) retrospektif olarak değerlendirildi (Tablo 1). Hastaların tüm radyolojik görüntüleri ile ameliyat öncesi, ameliyat sırası ve ameliyat sonrası verileri incelenerek kaydedildi. Çalışma etik kurul onayı Çukurova üniversitesi tıp fakültesi etik kurulundan alındı. Hastalara endovasküler tedavi hakkında gerekli bilgi verilerek bilgilendirilmiş hasta onamları alındı.

Otuz iki hastanın 19’u (\%59.4) asemptomatikti ve aort patolojileri başka bir hastalıktan dolayı görüntüleme yapılırken tesadüfen saptandı (Tablo 2). Geriye kalan 13 hasta (\%40.6) semptomatik olup hemen hepsinde ortak semptom bele ve sirta yayllan karın ağrısıydı. Hastaların 29'unda (\%90.6) fuziform, 3’ünde (\%9.4) sakküler anevrizma tespit edildi (Tablo 2). Tüm hastalarda aort anevrizmasına eşlik eden en az bir hastalık veya risk faktörü vardı. Risk faktörleri Tablo 1'de verilmiştir. Hastaların hepsine elektif şartlarda endovasküler tedavi uygulandı.

Hastalara işlem öncesi $3 \mathrm{~mm}$ kesit kalınlığında bilgisayarlı tomografi (BT) anjiyografi çektirilerek anatomik olarak endovasküler tamire uygun olup olmadıkları belirlendi (Şekil 1). Bilgisayarlı tomografi anjiyografi üzerinde gerekli ölçümler yapılarak uygun boyutlarda stent-greft seçimi yapıldı.

\section{İzlem}

Takipler; 1, 3, 6. aylarda ve daha sonra yılda bir kez BT anjiyografi ile gerçekleştirildi (Şekil 2, Tablo 3). Bilgisayarlı tomografi anjiyografi incelemesi stentgreft konulan hastalarda diyafragmadan femoral arterlere kadar $3 \mathrm{~mm}$ kalınlığında aksiyel planda kontrastlı kesitler alınarak elde edildi 
Tablo 1. Cinsiyet, yaş, semptomların varlığ1 ve anevrizma çapı

\begin{tabular}{|l|c|}
\hline Parametreler & Say1 \\
\hline Cinsiyet (E/K) & $30 / 2$ \\
\hline Yaş (yıl) & $65.1 \pm 8.8(32-84)$ \\
\hline Asemptomatik & 19 \\
\hline Semptomatik & 13 \\
\hline Anevrizma Çap1 & $60.5 \pm 12.4 \mathrm{~mm}(51.3-87.6 \mathrm{~mm})$ \\
\hline Erkek & $62.7 \pm 11.0 \mathrm{~mm}(52.3-87.6 \mathrm{~mm})$ \\
\hline Kadın & $53.3 \pm 5.9 \mathrm{~mm}(51.7-72.8 \mathrm{~mm})$ \\
\hline
\end{tabular}

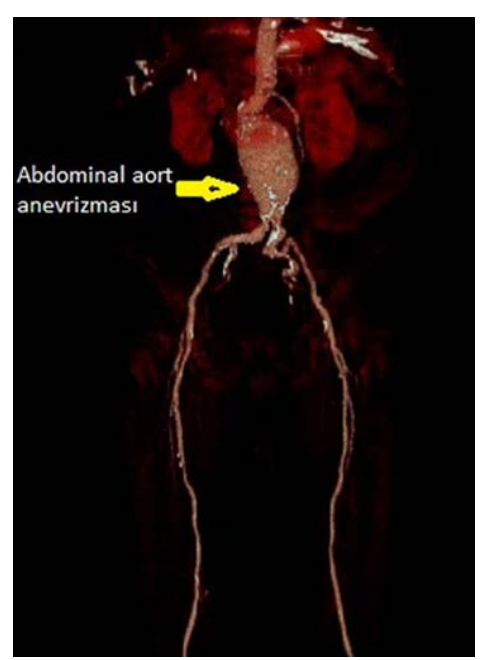

Şekil 1. Preoperatif üç boyutlu Kontrast Tomografik Anjiyografi ile abdominal aort anevrizması gösterimi.

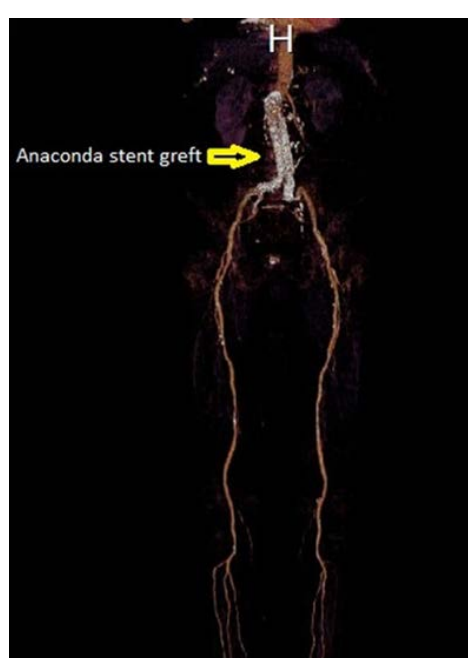

Şekil 2. Anakonda stent greft ile tamir yapılmış abdominal aort anevrizmasının üç boyutlu Kontrast Tomografik Anjiyografi ile gösterimi.

Tablo 3. Takip sürelerinin dağılımı

\begin{tabular}{|l|c|c|}
\hline & Frekans (n) & Yüzde (\%) \\
\hline Geçerli & & 9.4 \\
\hline $1-6$ ay & 3 & 31.3 \\
\hline Altı ay üzeri & 10 & 34.4 \\
\hline Bir yll üzeri & 11 & 25 \\
\hline İki yll üzeri & 8 & 100 \\
\hline Toplam & 32 & \\
\hline
\end{tabular}

\section{İstatistiksel analiz}

Verilerin istatistiksel analizinde SPSS 20 paket programı kullanılmıştır. Sayısal ölçümler ortalama ve standart sapma (gerekli yerlerde ortanca ve minimum - maksimum) olarak özetlenmiştir. Veriler yüzdesel olarak belirtilmiştir.

\section{BULGULAR}

Hastaların cinsiyet, yaş, semptomları ve anevrizma çapları Tablo 1 de verilmiştir. Hastalar etyolojilerine göre değerlendirildiğinde 19 hasta asemptomatik idi ve aort patolojileri başka bir hastalıktan dolayı görüntüleme yapilırken tesadüfen saptandi. 
Geriye kalan 13 hasta semptomatik idi ve hastaların büyük bölümünde ortak semptom sırta vuran karın ağrısıydı. Semptomatik olan bu hastaların hepsinde aortik patolojiye eşlik eden en az bir hastalık vardı (Tablo 2).

Endovasküler aortik tamir uygulanan hastaların anevrizma çap ortalamaları $60.5 \pm 12.4 \mathrm{~mm}$ (dağıllım 51.3-87.6 mm) olarak tespit edildi. Bu oran erkek hastalarda ortalama $62.7 \pm 11.0 \mathrm{~mm}$ (dağ llim 52.3$87.6 \mathrm{~mm}$ ) iken kadın hastalarda ortalama 53.3 \pm 5.9 mm (dağılım 51.7-72.8 mm) olarak belirlendi. İşlem öncesi öz geçmişlerinde en sik karşılaşılan ek hastalıklar, hastaların 30'unda hipertansiyon (HT), 12'sinde diabetes mellitus (DM), 15'inde koroner arter hastalığ1 $(\mathrm{KAH})$ ve 9'unde kronik obstrüktif akciğer hastalığı (KOAH) olarak gözlendi. Hastaların ameliyat öncesi ek hastalıkları Tablo 2'de verilmiştir.

Tablo 2. Ek hastalıkların yüzdesel dağılımı

\begin{tabular}{|l|c|c|}
\hline Parametreler & Say1 & Yüzde \\
\hline Yaş $(\geq 75$ yll & 4 & 12.5 \\
\hline Hipertansiyon & 30 & 93.8 \\
\hline Kardiyak hastalı* & 15 & 46.9 \\
\hline Periferik vasküler hastalık & 13 & 40.6 \\
\hline Kronik obstrüktif akciğer hastalığ1 & 9 & 28.1 \\
\hline Malignite** & 3 & 9.4 \\
\hline Diabetes mellitus & 12 & 37.5 \\
\hline Sigara öyküsü & 26 & 81.2 \\
\hline Geçirilmiş laparotomi & 2 & 6.3 \\
\hline Obezite & 16 & 53.1 \\
\hline
\end{tabular}

*Kapak hastalı̆̆ı, aritmi, konjestif kalp yetmezliği ve koroner revaskülarizasyonu içerir; ** Mide kanseri ameliyatı ( $\mathrm{n}=1$ ), akciğer kanseri ameliyat $(n=1)$, kan kanseri $(n=1)$

\section{Erken dönem}

Tüm hastalarda stent-greft implantasyonu başarıyla gerçekleştirildi (teknik başarı: \%100). İşlem sırasında açık ameliyata gereksinim duyulacak rüptür gibi major komplikasyon ya da mortalite olmadi (Tablo 4). Hiç bir hastada transfüzyon ihtiyacı olacak kanama gözlenmedi. İşlem sırasında, stent greftlerin yerleştirilmesi sonrası elde edilen kontrol anjiyografilerde 4 hastada (\%12.5) kaçak izlendi (Tablo 4). Bu kaçakların 3'ü (\%9.4) tip 1 iken biri (\%3.1) tip 2 idi. Tip 3 ve tip 4 kaçak izlenmedi. Tip 1 kaçak izlenen hastaların hepsine işlem esnasında aortik balon dilatasyon işlemi uygulandi. Bunun sonucunda hastada tip 1 kaçak tamamen kaybolduğu belirlendi. 1 hastada tip 2 endoleak belirlendi ancak çok ciddi olmadığı ve heparin etkisiyle kaçağın görüldüğü düşünülerek işlem yapılmadı.

Tablo 4. Komplikasyon ve mortalite oranları

\begin{tabular}{|l|c|c|}
\hline Komplikasyon & Say1 & Yüzde (\%) \\
\hline Stent migrasyonu & - & - \\
\hline Kaçak & 4 & -5 \\
\hline Transfüzyon gerektirecek kanama & - & 6.3 \\
\hline Greft bacağında tıkanılklı & 2 & - \\
\hline Anevrizma Çap artı̧ı & - & - \\
\hline İliyak anevrizma nüksü & - & - \\
\hline Yeniden girişim gereği & - & - \\
\hline İşlem sırasında mortalite & - & 3.1 \\
\hline İlk 30 günlük mortalite & 1 & - \\
\hline Anevrizma ile ilgili mortalite & - & 3.1 \\
\hline Toplam mortalite & 1 & \multicolumn{2}{c|}{} \\
\hline
\end{tabular}

İşem sonrası gözlem amaçlı 4 hasta 1 gün süre ile yoğun bakımda takip edildi. Diğer tüm hastalar yoğun bakım ihtiyacı olmadan serviste takibe alındı.
Hiçbir hastada kan transfüzyonu ihtiyacı olmadi. Tüm hastalar ameliyat sonrası 12 . saatte mobilize edildikten sonra birinci günde taburcu edildi. İşlem 
sonras1 bir hastada (\%3.1) kontrast madde toksisitesine bağlı kreatin düzeyinde geçici olarak yükselme gözlendi (1 hastanın ameliyat öncesi ortalama kreatin değeri: 1.5 , ameliyat sonrası birinci günde ortalama kreatin değeri: 1.9, ameliyat sonrasi birinci ayda ortalama kreatin değeri: 1.1).

Erken dönemde bir erkek hastada sağ bacak ağrısı şikayeti ile birinci haftada anaconda greftin sağ iliak bacağında tromboze oklüzyon tespit edilerek femoral embolektomi işlemi ile iliak bacak temizlenerek açıldı. Bir erkek hastada 1.5 ay sonra akut miyokard infarktüsü sonrası mortalite gözlendi. Birinci ay kontrol BT anjiyografi incelemesinde tip 2 kaçağı olan bir hastanın kaçağının kaybolduğu.

\section{Orta dönem}

Altınc1 ay takiplerinde bir erkek hastanın anevrizma çapında hafif atma olduğu ancak kontrast geçişi olmadığ1 için kollateral systemden kaynaklandığ1 düşünülerek takibe devam edilmesi planlandi. Bir erkek hastada dördüncü ayda anaconda stent greftin sağ iliak bacağında tromboze oklüzyon geliști. Bunun sebebinin hastanın iliak damarındaki yaygin plak formasyonu olduğu belirlenerek hastaya sol iliyo-sağ iliak ptfe greft bypass operasyonu yapıldı.

Bir yıl üzeri takipte 11 hastaya (\%34.4), iki y1l üzeri takipte 8 hastaya $(\% 25)$ ulaşılmış iken kontrollerde kaçağa, yer değiştirmeye ve stent-greftte kırılmaya rastlanmadı (Tablo 4). Bir y1l üzeri takipteki 19 hastanin kontrollerinde 7 hastada (\%36.8) anevrizma çapında gerileme görülürken, 12 hastada $(\% 63,1)$ anevrizmanın tamamen tromboze olarak çapin sabit kaldığ1 gözlendi. Birinci y1l kontrolüne gelmeyen ve antiagregan ilaçlarını kendi inisiyatifi ile kesen, iki taraflı böbrek arterlerine yönelik baca yapılan bir hastada böbrek stentlerinin tıkanmasına bağlı olarak akut böbrek yetmezliği gelişti ve diyaliz gereksinimi oldu. Erken ve orta dönem değerlendirmesinde kadın hastalarda morbidite ve mortalite görülmemiştir. Ancak kadın hasta sayısının çok az olması bu karşılaştırmayı göz ardı etmemize neden olmuştur.

\section{TARTIŞMA}

Anevrizmalar, genellikle olması gereken lümen çapının \%50'sinden daha fazla genişlemiş olan lokal dilatasyonlar olarak tanımlanır. Aortik anevrizmaların çoğu (\%95) infrarenal abdominal aortta görülür. Torasik ve torakoabdominal aort çap1, infrarenal abdominal aorttan daha geniştir ve bu bölgelerdeki anevrizmal dejenerasyon buna göre tanımlanır.

Aort anevrizmalarının tedavisinde iki seçenek vardır: İlki açık cerrahi rezeksiyon ve anevrizmal segmente prostetik greft yerleştirilmesini içeren konvansiyonel açık cerrahi yöntem; diğeri ise açık cerrahi ile karşılaştırıldığında minimal invaziv bir yöntem olan endovasküler stent-greft yerleştirilmesidir. Teknolojik gelişmelere ve deneyim artışına rağmen abdominal aort anevrizmasinın açık cerrahi tamirinde hastane mortalitesinin yaklaş1k $\% 5$, komplikasyon oranının ise \%20'ye yakın olması yeni tedavi seçeneklerini gündeme getirmiştir ${ }^{8}$. Abdominal aort anevrizmalı hastaların önemli kısmında genellikle riski artıran morbidite faktörleri bulunmaktadır. $\mathrm{Bu}$ hastaların \%22'sinde kronik obstrüktif akciğer hastalı̆̆1, \%10’unda şeker hastalığ1 ve \%7.2'sinde böbrek yetmezliği vardır?.

Rutin aortik stent-greft tedavisi için bazı anatomik şartlar gerekmektedir. Abdominal aort çap1 5.5 cm'nin üzerinde olmall, böbrek arterlerinin alt kesiminde stentgreftin yerleşmesi için en az 10-15 mm uzunluğunda sağlam aort duvarı bulunmalı, tutunma bölgesi trombüs ve çevresel kalsifikasyon içermemeli, stent-greftin taşınabilmesi için iliyak arterlerin çapları uygun genişlikte olmalı, anevrizma boyun açısı 60 derecenin altında ve iliyak açlanma 90 derecenin üzerinde olmalıdır ${ }^{10}$.

Anatomik kriterler içinde en önemlisi proksimaldeki sağlam aort boynunun çapı, kalitesi ve uzunluğudur. Yerleştirilecek stent-greftin proksimal çapı sağlam aort boyun çapinın \%10-30 fazlasi olarak hesaplanmalıdır. Gerektiğinden daha küçük ve daha büyük stent-greft seçimi proksimal tip 1 kaçak riskini artırırken, ayrıca daha büyük seçim ileride sağlam aort boynunda genişlemeye neden olmaktadır. Günümüzde, teknolojik gelişmeler ve piyasaya yeni çıkan stent-greftler ile birlikte anevrizma boyun açısı 90 derece olan hastalar da tedavi sınırına girmiştir.

Infrarenal abdominal aort anevrizmalarda son yirmi yıldır tedavi yaklaşımı değişmiştir ${ }^{11,12}$. Açık cerrahiye kıyasla daha az invaziv, ameliyat sirası mortalite ve morbiditesi düşük, daha kısa hastanede kalış süresi ve daha az kan transfüzyonu gereksinimi doğuran EVAR, uygun anatomiye sahip, daha s1k ve komplike eşlik eden hastalığ1 olanlarda uygulanmaya başlanmışı ${ }^{13,14}$. Bu avantajlarının yanında ameliyat sonrası tekrarlayan girişimler ve sıkça görülen kaçak dezavantajlarıdır ${ }^{15-16}$. Kanada'da yapılan çift merkezli 
randomize bir çalışmada; Abdominal aort anevrizma'larda açı cerrahi ve EVAR yapilan olgular arasında yaşam kalitesi, SF 36 kullanılarak hastaların kendi değerlendirmeleri 1şı̆̆ında karşılaştırılmış ve istatistiksel veriler elde edilmiştir. $\mathrm{Bu}$ çalışmada sonuç olarak açık cerrahi yapılan hastalarda yaşam kalitesi ölçeklerinde uzun dönemde anlamlı bir yükseklik bulunmuştur ${ }^{17}$. Ancak bu çalışma tamamiyle hasta beyanına dayalı olup, sonuçları bizce tartışmaya açıktır. Çalışmamızda hastalara ait birçok değişken parametre, kendi aralarında ve SF 36 ölçekleri ile kıyaslanarak, EVAR hasta grubunun kısa ve orta dönem yaşam kalitesinin daha iyi olduğu bulundu. Eşlik eden hastalık ve ameliyat sonrası komplikasyon durumunda yaşam kalitesi ölçeklerinin düştüğü, hastanede kalış süresinin artmasının yaşam kalitesi ölçeklerini olumsuz etkilediği, EVAR hasta grubunda komplikasyon insidansının daha düşük olduğu ve hastanede kalış sürelerinin kısaldığı görüldü.

Yapılan çalışmalar, endovasküler anevrizma tedavisinin standart cerrahi yönteme göre hastanede kalış süresini \%60-65 oranında kısalttığını (1-3 gün) ve hastalarda meydana gelen kan kaybinı \%25-40 oranında azalttığını ortaya koymuştur ${ }^{12,13}$. Bizim çalışmamızda da tedavi edilen tüm hastalar ameliyat sonrası birinci günde taburcu edildi ve hiçbir hastada kan transfüzyon ihtiyacı olmadı. Ayrıca endovasküler yöntemde retroperitoneal bölgedeki sempatik ve parasempatik innervasyonun bozulmaması, genç hastalarda oluşabilecek cinsel işlev bozukluğunun önlenmesi bakımından önemli bir avantajdır.

Hollanda'da Dutch Randomize Endovasküler Anevrizma uygulaması çalışması ve İngiltere'de açık cerrahiye kıyasla endovasküler anevrizma tamiri olmak üzere iki farklı geniş kapsamlı randomize çalışma yapılmıştır. Her iki çalışmada da endovasküler anevrizma tamiri uygulanan hastalarda ameliyat süresi, transfüzyon gereksinimi ve yoğun bakımda kalış süresi anlamlı şekilde az olmuştur ${ }^{14}$. Endovasküler aort tamirinin kendine özgü bazı dezavantaj ve komplikasyonları bulunmaktadır. Hastanın belirli aralıklarla devamlı BT takibinde olmas1 ve bu nedenle ek radyasyona maruz kalmas1 en önemli dezavantajdır. Bu nedenle eskiden hastalar ameliyat sonrası dönemde sı aralıklarla takip edilirken, günümüzde daha az aralıklarla takip edilmeye başlanmıştır. Bunun yanında bazı merkezlerde radyasyondan kaçınmak için manyetik rezonans görüntüleme ve Doppler ultrasonografi de takipte kullanılmaktadır. Bununla birlikte günümüzde halen aortik stent-greft takibinde altın standart inceleme BT anjiyografidir. Aortik stentgreft işlemine özel komplikasyonlar arasında yer değiştirme, kaçak, greft bacağında tromboz ve kıvrılma sayılabilir. Bu komplikasyonlar nedeniyle sekonder girişim endovasküler tedavinin dezavantajlarından diğerini oluşturmaktadır. Kaçak, endovasküler greftlemeden sonra en sık karşılaşılan sorundur. Çeşitli çalışmalarda \%11-44 oranlarında kaçak sorunuyla karşılaşıldığı bildirilmiştir ${ }^{15,16}$. Bizim çalışmamızda da erken dönemde kaçak saptananların oran1 \%10.8 iken, bu hastaların takibinde sekonder girişimlerin de katkısıyla kaçak oranı sıfıra indi. Anevrizma kesesinden çıkan patent arterlerin sayısı ile kaçak gelişimi arasında anlamlı bir ilişki vardır ${ }^{17}$ Endovasküler girişimden hemen sonra ortaya çıkanlar primer kaçak, geç dönemde ortaya çıkanlar ise seconder kaçak olarak adlandırılmaktadır ${ }^{18}$. Sekonder kaçak, greftin yer değiştirmesi, fiksasyon bölgelerindeki damar çapinın zaman içerisinde genişlemesi, greft materyalinde aşınma ya da anevrizma kesesindeki morfolojik değişikliklerden kaynaklanmaktadır.

Anevrizma boyun segmenti kısa olan, boyun açısı 60 dereceden fazla olan, anevrizma boynunda trombüs ya da plak olan hastalarda tip 1 kaçak görülme riski daha fazladır. Tip 1 kaçaklar anevrizma içi basıncı sistemik basınç ile eşit hale getirir ve rüptür riskini artırır bu nedenle tip 1 kaçaklar tedavi edilmelidir ${ }^{19}$. Bizim çalışmamızda da boyun açısı 60 dereceden fazla olan üç hastada (ortalama boyun açısı 71.6) tip 1 kaçak görüldü. Ayrıca bir hastanın boyun bölgesinde trombüs vardı. Bu hastaların takiplerinde anevrizma çapında artış olmadı.

İnternal iliyak arterler anevrizmaya iştirak ediyor ise tip 2 kaçak oluşumunu engellemek için internal iliyak arterler kapatılarak endovasküler tedavi yapılabilmektedir ${ }^{20}$. Biz de bu amaçla iki hastada stentin iliak bacağına ek iliak stent greft ekleyerek internal iliak arteri kapattık. Bununla birlikte, bu hasta grubunda internal iliyak arterin korunması diğer bir seçenek olarak karşımıza çıkmaktadır. Internal iliyak arteri korumak için ya iliyak dallı endogreft ya da paralel greftleme teknikleri kullanılabilir.

Endovasküler işlemin başarılı sayılabilmesi için, arteriyel sisteme komplikasyonsuz girilmesi, greftin proksimal ve distal kaçak olmadan tutunması, greftte kıvrılma, tıkanma ve yer değiştirme olmaması, önemli dallarda malperfüzyon olmaması gereklidir. Ayrica başarıda hasta ve hastaya uygun stent-greft 
seçiminin, kısa boyunlu ve boyun açısı yüksek hastalarda daha dikkatli davranılmasının ve kaçakların takip edilerek yine endovasküler yöntemle tedavi edilmesinin de önemli payı olduğunu düşünmekteyiz. Çalışmamızda orta dönem takipteki hasta sayısı az olmasina rağmen sonuçlar iyidir. İlerleyen yıllarda hasta sayisinin artmasi ve takip süresinin uzaması ile birlikte daha kesin veriler elde edeceğimiz kanaatindeyiz. Erken ve orta dönem kısıtlı zaman aralığında hasta sayısının az olması, çalışmanın sonucu açısından limitasyon oluşturmaktadır. Daha uzun dönemi içeren büyük hasta popülasyonu ile yapılacak çalışmanın bu limitasyonu ortadan kaldıracağını düşünmekteyiz.

Sonuç olarak, abdominal aort anevrizması için elektif uygulanan endovasküler tedavi ile kan kayb1, yoğun bakım ve hastanede kalış süresi, erken dönem mortalite ve morbidite oranları oldukça düșüktür. Greft teknolojilerindeki gelişmelere ve deneyim artışlarına paralel olarak kaçak oranlarının azaltılmasıyla birlikte endovasküler aortik tamir yöntemleri gelecekte abdominal aort anevrizmas1 tedavisinde birinci seçenek olma yolunda ilerlemektedir.

\section{KAYNAKLAR}

1. Sanfelippo PM. Abdominal aortic aneurysm: what we know, what we don't know-a review. Int J Angiol. 2003;12:145-52.

2. Zeinali AMH, Marzban M, Zafarghandi M, Shirzad M, Shirani S, Mahmoodian R et. al. Endovascular Aortic Aneurysm and Dissection Repair (EVAR) in Iran: descriptive midterm follow-up results. Iran J Radiol. 2015;13:16021

3. Sönmez B, Arbatlı H, Yağan N, Arpaz M, Demirsoy E, Tükenmez $F$ et al. Aort Hastalıklarında Endovasküler Gelişmeler. İstanbul, Çapa Tip Kitabevi. 2004.

4. Greenhalgh RM, Brown LC, Kwong GP, Powell JT, Thompson SG; EVAR trial participants. Comparison of endovascular aneurysm repair with open repair in patients with abdominal aortic aneurysm (EVAR trial 1), 30-day operative mortality results: randomised controlled trial. Lancet. 2004;364:843-8.

5. Moore WS, Rutherford RB. Transfemoral endovascular repair of abdominal aortic aneurysm: results of the North American EVT phase 1 trial. EVT Investigators. J Vasc Surg. 1996;23:543-53.

6. Cuypers P, Buth J, Harris PL, Gevers E, Lahey R. Realistic expectations for patients with stent-graft treatment of abdominal aortic aneurysms. Results of a European multicentre registry. Eur J Vasc Endovasc Surg. 1999;17:507-16.

7. Mazzei MA, Guerrini S, Mazzei FG, Squitieri NC, Notaro D, de Donato $G$ et. al. Follow-up of endovascular aortic aneurysm repair: Preliminary validation of digital tomosynthesis and contrast enhanced ultrasound in detection of medium- to long-term complications. World J Radiol. 2016;8:530-6.

8. Yavuz Ş, Özbudak E, Gümüştaş S, Kanko M, Çiftçi E, Berki T. Abdominal aort anevrizmalarında endovasküler stent gwreft uygulamalar1: Orta ve uzuzn dönem sonuçlar. Türk Göğüs Kalp Damar. 2013;21:333-40.

9. Parodi JC, Bates MC, Puech-Lao P. Aortic endovascular cotroversies and challenges; The main EVAR indication will be patients unfir for open repair. In: Greenhalgh RM, editors. The Evidence for Vascular or Endovascular Reconstruction. 13945. London, W.B. Saunders. 2002.

10. García-Madrid C, Josa M, Riambau V, Mestres CA, Muntaña J, Mulet J. Endovascular versus open surgical repair of abdominal aortic aneurysm: a comparison of early and intermediate results in patients suitable for both techniques. Eur J Vasc Endovasc Surg. 2004;28:365-72.

11. Duarte MP, Maldjian CT, Laskowski I. Comparison of endovascular versus open repair of abdominal aortic aneurysms: a review. Cardiol Rev. 2009;17:1124.

12. Ballard JL, Abou-Zamzam AM, Teruya TH, Bianchi C, Petersen FF. Quality of life before and after endovascular and retroperitoneal abdominal aortic aneurysm repair. J Vasc Surg. 2004;39:797-803.

13. Güneş T, Yılık L, Yetkin U, Yürekli I, Özcem B, Yazman $S$ et al. Abdominal aort anevrizmasi tamirinde açık konvansiyonel ve endovasküler cerrahi tedavinin karşılaştırılması. Türk Göğüs Kalp Damar. 2012;20:515-23.

14. Blankensteijn JD, de Jong SE, Prinssen M, van der Ham AC, Buth J, van Sterkenburg SM, et al. Twoyear outcomes after conventional or endovascular repair of abdominal aortic aneurysms. $\mathrm{N}$ Engl J Med. 2005;352:2398-405.

15. Köksal C, Özcan V, Sarıkaya S, Meydan B, Zengin M, Numan F. Supplemental vascular procedure for endovascular aneurysm repair. Türk Gögüs Kalp Damar. 2004;12:254-8.

16. Zarins CK, Wolf YG, Lee WA, Hill BB, Olcott C IV, Harris EJ et al. Will endovascular repair replace open surgery for abdominal aortic aneurysm repair? Ann Surg. 2000;232:501-7.

17. Beebe HG, Cronenwett JL, Katzen BT, Brewster DC, Green RM; Vanguard Endograft Trial Investigators. Results of an aortic endograft trial: impact of device failure beyond 12 months. J Vasc Surg. 2001;33:55-63. 
18. Aljabri B, Al Wahaibi K, Abner D, Mackenzie KS, Corriveau MM, Obrand DI, et al. Patient-reported quality of life after abdominal aortic aneurysm surgery: a prospective comparison of endovascular and open repair. J Vasc Surg. 2006;44:1182-7.

19. Parıldar M, Posacioğlu H. Endovasküler aortik anevrizma tamiri sonrası görülen kaçaklar: Tanım ve tedavi. Türk Göğüs Kalp Damar. 2011;19:46-50.
20. Criado FJ, Wilson EP, Velazquez OC, Carpenter JP, Barker C, Wellons E et al. Safety of coil embolization of the internal iliac artery in endovascular grafting of abdominal aortic aneurysms. J Vasc Surg. 2000;32:684-8. 